\title{
Chlorpheniramine impairs spatial choice learning in telencephalon-ablated fish
}

\author{
FERNANDA ROMAGUERA and ROSANA MATTIOLI
}

Laboratory of Neuroscience, Physiotherapy Department, Center of Biological Sciences and Health, Universidade Federal de São Carlos, São Carlos, São Paulo, Brazil.

\begin{abstract}
This work investigated the effect of the $\mathrm{H}_{1}$ receptor blockade in the forebrain of ablated Carassius auratus in a simple stimulus-response learning task using a T-maze test with positive reinforcement. The goldfish were submitted to surgery for removal of both telencephalic lobes five days before beginning the experiment. A Tshaped glass aquarium was employed, with two feeders located at the extremities of the long arm. One of the two feeders was blocked. The experimental trials were performed in nine consecutive days. Each fish was individually placed in the short arm and confined there for thirty seconds, then it was allowed to swim through the aquarium to search for food for ten minutes (maximum period). Time to find food was analysed in seconds. Animals were injected intraperitoneally with chlorpheniramine (CPA) at $16 \mathrm{mg} / \mathrm{kg}$ of body weight or saline after every trial, ten minutes after being placed back in the home aquarium. The results show that all the training latencies of the A-SAL group were higher than the latencies of the S-SAL group. The S-SAL group had decreased latencies from the second trial on, while the S-CPA group showed decreased latencies after the fourth trial. The A-SAL group showed reduced latencies after the fifth trial, but the A-CPA group mainteined the latencies throughout the experiment. This suggests that CPA impairs the consolidation of learning both on telencephalon ablated animals and in sham-operated ones through its action on mesencephalic structures of the brain and/or on the cerebellum in teleost fish.
\end{abstract}

Key terms: histamine, learning, teleost fish, telencephalon.

\section{INTRODUCTION}

Histamine, one of the biogenic amines, has received much attention in recent years as a neurotransmitter and neuromodulator in the brain. Histaminergic neurons appear to be involved in many functions, such as arousal (Tuomisto et al., 2001), memory (Passani et al., 2000) and feeding (Morimoto et al., 2001). In particular, the $H_{1}$ receptor plays a role in several intracellular processes, mediating excitatory actions on whole brain activity (Haas and Panula, 2003; Monti, 1993), and is also intrinsically involved in the facilitating effects of histamine in the hippocampus of rats (Huang et al., 2004). Furthermore, histamine might also be important for processes involving neurogenesis and functional neural recovery
(Brown et al., 1995; Weiler et al., 1990; Weiler et al., 1992). The cellular actions of histamine on synaptic plasticity are consistent with a role for histamine in learning and memory.

However, research results on the effects of histamine on learning, memory and reinforcement processes have not been conclusive (Blandina et al., 1996; Cangioli et al., 2002; Passani et al., 2001), either because of the lack of specific methodologies for investigating this neural system or histamine is modulating the behavioral components that affect learning and memory. Some studies have demonstrated a facilitating role of histamine in learning and memory processes (De Almeida; Izquierdo, 1986; Meguro et al., 1995; Miyazaki et al., 1995;

Corresponding author: Fernanda Romaguera*. Address: Rodovia Washington Luís, km 235, Departamento de Fisioterapia Laboratório de Neurociências, São Carlos - SP - Brazil, CEP 13565-905, Phone number: +55 (16) 3351-8628, Fax number: +55 (16) 3361-2081, e-mail address: feromaguera@yahoo.com.br 
Prast et al., 1996). On the other hand, other works suggests that the neural histaminergic system acts as an inhibitor of this process (Kamei et al., 1993; Mattioli et al., 1998, Medalha et al., 2000).

The histaminergic system is a phylogenetically old group of neurons that project to many parts of the central nervous system (CNS). Teleost fish are phylogenetically closer to the basic vertebrate blueprint than higher vertebrates, and appear to have a simpler histaminergic system in terms of fiber density, area of innervation (Inagaki et al., 1991) and, contrary to higher vertebrates, brain histamine seems to be strictly neuronal (Eriksson et al., 1998). In addition, neuroanatomical and neurobehavioral studies indicate that teleost and mammalian histaminergic systems have some parallel functions and that this system has been well preserved through evolution (Kaslin and Panula, 2001; Portavella and Vargas, 2005). Therefore, teleosts are suitable for studying histamine as a neurotransmitter and neuromodulator in the CNS (Choich et al., 2004).

Research studies on learning and memory appear to be a powerful tool for the comparative study of cognition. Knowledge of cognitive capabilities and their neural basis in fish could contribute to the understanding of the evolution of the brain and behavior in vertebrates. The teleost telencephalon, which was once considered an olfactory system, is now known to be involved in more complex functions. Past and recent neuroanatomical and behavioral evidence suggests that telencephalic ablation does not affect simple instrumental learning and classical conditioning (Hollis and Overmier, 1982; Overmier and Curnow, 1969). Nevertheless, it might impair other processes related to learning and memory, such as nonspecific arousal (Peeke and Gordon, 1981), short-term memory (Laming and Mckinney, 1990; Ohnishi, 1997) and habituation (Flood et al., 1976; Laming and Mckee, 1981). In addition, it also prejudices spatial learning and memory (Salas et al., 1996a), both emotional and spatial/temporal (or relational), respectively associated with the dorsomedial and dorsolateral telencephalon
(Portavella et al., 2002).

The histaminergic system in teleostean fish projects to the telencephalon in a single way and has a dense cluster of histaminergic neurons at the diencephalon, mesencephalon and rostral parts of the rhombencephalon (Kaslin and Panula, 2001). Given that previous studies have shown a facilitating role of CPA on appetitive learning in intact fish (Medalha and Mattioli, 2007), we questioned if the telencephalon or other structures of the teleostean brain are responsible for the action of histamine in this task. The hypothesis is that the removal of the telencephalon could suppress the effect of CPA. Thus, the goal of this study was to investigate the effect of the $\mathrm{H}_{1}$ receptor blockade in a simple stimulus-response learning in forebrain of ablated Carassius auratus, using a T-maze test with appetitive reinforcement.

\section{MATERIALS AND METHODS}

\subsection{Subjects}

Sixty-nine experimental naive goldfish (C. auratus), obtained from a local supplier, were kept in stock tanks for acclimatization for a minimum of three weeks before the beginning of the experiment. The fish were kept in aerated filtered water $\left(22 \pm 2^{\circ} \mathrm{C}\right)$ under natural light cycle and were fed five times per week with flake food for ornamental fish ("Super Red", Hai Feng, Formosa).

The fish, weighing 6-12 g, were distributed in groups of 10-15 individuals and housed in glass aquaria during recovery after surgery and throughout the experiment. During the recovery period they were fed from PVC-made feeders with small pellets for goldfish ("Fast Color", Hai Feng, Formosa). During the experiment, the fish were fed only with the small pellets they obtained in the daily experimental session.

\subsection{Surgical Procedure}

Before surgery, the goldfish were randomly distributed into two groups. One group was telencephalon ablated $(n=30)$ and the other 
also underwent surgical procedure, but without surgical brain damage $(n=39)-$ sham operated. Previous to surgical procedures, the telencephalon-ablated fish were anesthetized by immersion in a $0.8 \mathrm{~g} / \mathrm{l}$ solution of tricaine methanosulfonate (TMS) - (3-aminobenzoic acid ethyl ester methasulfonate, Sigma Chemical, St. Louis, MO) until breathing ceased. Each fish was then placed in the surgical apparatus where it remained fixed in place by lateral holders and half immersed in water. An adjustable tube was inserted into its mouth to insure a constant flow of aerated water through the gills. The concentration of anesthetic in the water was maintained at $0.3 \mathrm{~g} / \mathrm{l}$ during surgery. The dorsal skin and skull were carefully removed with a driller under visual control to expose the brain. Both telencephalic lobes and the olfactory bulb were aspirated with a glass pipette connected to a manual vacuum system (figure 1). After ablation, the skull was covered with fast drying dental cement (Acrílico Auto-Polimerizante Clássico, JET, SP, Brasil and Líquido Acrílico AutoPolimerizável, Dental VIPI Ltda, SP, Brasil). The fish was then placed in a glass aquarium for a recovery period of five days before the behavioral tests.

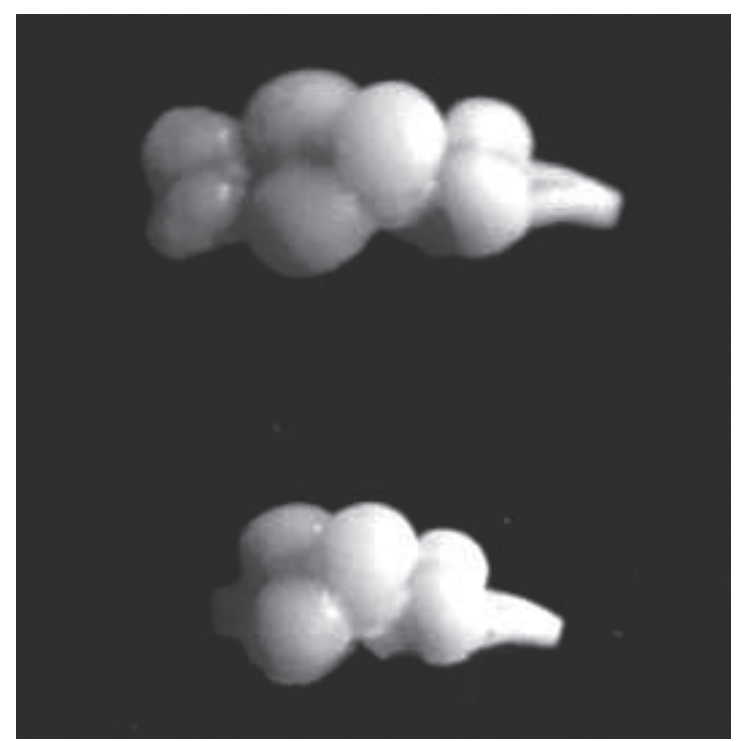

Figure 1: An example of brains from an intact fish (top), and a telencephalon-ablated fish (bottom).

\subsection{Pharmacological Treatment}

Chlorpheniramine maleat salt (CPA) is an $\mathrm{H}_{1}$ selective receptor antagonist that readily passes the blood-brain barrier and can therefore be used for in vivo CNS studies (Leurs et al., 1995). CPA (Sigma Chemical Co., Saint Louis, MO) was dissolved in a saline solution and used at a dose of $16 \mathrm{mg} /$ $\mathrm{kg}$ of body weight, as previously applied in other studies of our laboratory (Faganello and Mattioli, 2007; Medalha and Mattioli, 2007). A saline solution was employed as experimental control. CPA and vehicle were blind-coded and injected intraperitoneally (i.p.) using a volume of $1 \mathrm{ml} / \mathrm{kg}$ of body weight. The fish were not treated through the water because this method would not allow for exact control of the absorption of the drug.

The fish submitted to telencephalic ablation were distributed into two groups, one treated with CPA (A-CPA, n=14) and the other with saline (A-SAL, $n=16)$. The fish submitted to sham surgery also received either $\mathrm{CPA}(\mathrm{S}-\mathrm{CPA}, \mathrm{n}=21)$ or saline (S-SAL, $\mathrm{n}=18$ ).

\subsection{Apparatus}

A T-shaped glass aquarium was used. The "T" stem was $20 \mathrm{~cm}$ long and $11.5 \mathrm{~cm}$ wide and the cross bar was $35.5 \mathrm{~cm}$ long and $9.5 \mathrm{~cm}$ wide. Two PVC tubes $(5 \mathrm{~cm}$ long and $2.5 \mathrm{~cm}$ in diameter) were attached to the opposite ends of the cross bar, and served as feeders. The intersection of the " $\mathrm{T}$ " had a guillotine-like sliding door that, when closed, left the " $T$ " stem as a startchamber.

\subsection{Behavioral Procedure}

The fish were food deprived for 48 hours prior to experimentation to enhance foraging activity. The experimental trials were performed on 9 consecutive days. On the first day an adaptation trial was performed for 10 minutes. At the beginning, the fish were individually placed in the start-chamber and confined there for 30 seconds. The sliding door was then raised, allowing the fish to swim throughout 
the aquarium. For adaptation, the fish were allowed to freely explore the maze and could access food in both feeders.

The training trials began ot the second day, when the entry of one of the feeders was randomly blocked for each fish with a thin net so that to get access to food the fish had to swim to the feeder in the opposite side of the long arm of the maze. The same side was blocked for each fish until the end of the experiment. The fish were placed individually in the experimental aquarium start-chamber. After 30 seconds the sliding door was raised, and the fish was allowed to swim freely throughout the aquarium for 10 minutes or until it found the food. In this case, the fish was allowed to feed for 2 minutes. The time spent to reach the food (latency) was recorded in seconds. The training sessions were limited to 10 minutes because a strong decrease in foraging activity after 10 minutes had been reported in earlier experiments (Spieler et al., 1999). Once the trial was finished, the fish was removed from the maze and returned to its home aquarium.

The fish were injected i.p. with CPA or vehicle 10 minutes after their return to the home aquarium. That period is in conformity with the one hour time window of memory consolidation for fish reported by Liu and Braud (1974).

\subsection{Statistical analysis}

The learning curves of all the groups for the dependent measure of latencies were analyzed via a three-way analysis of variance (ANOVA) with repeated measures. ANOVA included main effect, between-group measures of "exposure effect" (sham vs. ablation) and "drug effect', (saline vs. CPA), within groups repeated measure "trials"' (8 levels), and interactions among all of these. If a significant effect was found $(p<0.05)$, post hoc comparisons of treatment means on those factors were analyzed using the Student Newman-Keuls test $(\mathrm{p}<0.05)$. Decrease in latencies was considered as an indicator of learning.

\section{RESULTS}

The mean latencies of each group for each of the 8 training trials are shown in Figure 2. ANOVA results demonstrated significant interaction $\left(\mathrm{F}_{7,671}=4.08, \mathrm{p}=0.0004\right)$ between the repeated within factor (trials) and the other factors (ablation or drug).

All the training latencies of the A-SAL group were significantly higher than latencies of the S-SAL group (Student Newman-Keuls, $\mathrm{p}<0.05)$, suggesting that

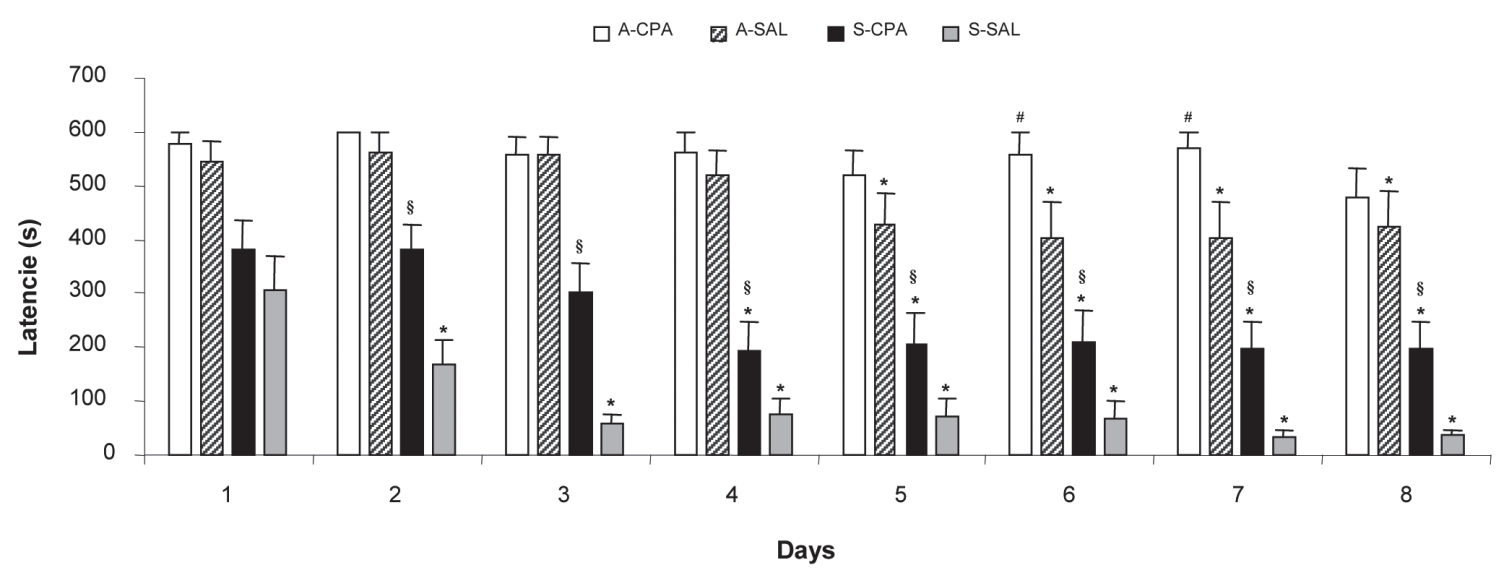

Figure 2: Latency for trials of ablation and sham groups. Data is presented as Mean+SEM. Student Newman-Keuls test: $\left[{ }^{*}\right]=\mathrm{p}<0.05$ compared to first trial; $[\#]=\mathrm{p}<0.05$ compared to A-SAL trials; $[\S]=\mathrm{p}<0.05$ compared to S-SAL trials. 
telencephalon removal impairs the fish performance on a spatial choice learning test.

Fish of the S-SAL group showed a significative decrease in latencies at the second trial and maintained that reduction until the end of the experiment (Student Newman-Keuls, $\mathrm{p}<0.05)$, while the S-CPA group demonstrated a decrease only after the fourth trial (Student Newman-Keuls, $\mathrm{p}<0.01)$. It can be suggested that the S-CPA group showed a delay of learning, since comparison between the S-SAL and S-CPA groups had also indicated statistical differences in trial latencies from the second trial until the end (Student NewmanKeuls, $\mathrm{p}<0.05)$. Additionally, while the ACPA group did not learn the task, the SCPA group did learn it, but with an important delay in comparison to the SSAL group.

In the A-CPA group, there were no differences in the latencies throughout the experiment (Student Newman-Keuls, $\mathrm{p}>0.05$ ), while the A-SAL group showed reduced latencies after the fifth trial (Student Newman-Keuls, $\mathrm{p}<0.05$ ). Thus, CPA also appears to impair learning in telencephalon ablated fish.

\section{DISCUSSION}

Present results illustrate impairment in the ability of fish to learn a spatial-choice task as a result of telencephalic ablation, concurring with the hypothesis that the teleost telencephalon has specific functions in learning and memory. These functions might be derived from separate neural substrata (Portavella et al., 2002) and provide a neural substratum for cognitive mapping in fish. In addition, other structures might be involved, as striatum and cerebellum, which make several connections with the telencephalon in fish (Broglio et al., 2003) and play a role in operant conditioning in mammals (Kandel et al., 2000).

The proposed task in this study involves a spatial component, the localization of the correct feeder. That skill is related to distinct spatial memory strategies, either allocentric or egocentric, those are most probably based on multiple spatial memory systems (Broglio et al., 2003). Telencephalic ablation results suggests a disruption of tasks that require place learning (allocentric) strategies, but not of tasks related to body turning or direction, which are simple spatial discriminations that require the use of a single cue for orientation (López et al., 2000a; López et al., 2000b; Portavella and Vargas, 2005; Salas et al., 1996a; Salas et al., 1996b). Once the feeder and the food was present in both sides of the proposed task, but reachable only in one, the animals probably used cues other than the ones provided by the experimental aquarium to solve the task, such as visual detection of the feeders. As well, the detection of odor could not influence the performance of the telencephalon-ablated animals, once they had their olfactory bulb removed on the occasion of surgery. Both factors indicate that those skills are not necessary to reach the food and also suggest that telencephalonless animals may use egocentric strategies to achieve learning.

However, extratelencephalic attentional systems exist, suggesting that the teleostean telencephalon has a supplementary role in the learning process and facilitates integration of neural events in other areas involved in that function (Ohnishi, 1997). The additional structures involved in spatial learning are the optic tectum (orienting responses and other motor processes) and cerebellum (associating of orientated motor responses with single landmarks) (Demski and Beaver, 2001). The optic tectum also receives projections of histaminergic neurons, which arrive to the telencephalon, diencephalon, mesencephalon and rostral parts of the rhombencephalon (Inagaki et al., 1991). Therefore, in the present work the $\mathrm{H}_{1}$ antagonist could be acting on the caudal projections of histaminergic neurons, since CPA caused similar effects in both groups - ablated or not -, inducing deficits in the consolidation of learning the task in these animals. These findings, and the data of previous studies (Ohnishi, 1997; Demski and Beaver, 2001), support the hypothesis that CPA does not act 
exclusively via telencephalon and could exert its function in mesencephalic structures of the brain (Faganello and Mattioli, 2005).

The results obtained in the present work show that CPA-treated fish had a delay in the consolidation and also impairment in the performance of a spatial-choice task. The locomotor activity does not seem to be the most important cause of this. Although deficits in locomotor activity have been related in telencephalonless fish (Shinozuka and Watanabe, 2004), a study conducted in our laboratory did not find any influence of the CPA on this behavior (Faganello, 2007). Previous studies pointed a facilitating role of CPA on similar appetitive tasks in intact goldfish (Medalha and Mattioli, 2007). However, our results indicate an opposite effect of CPA on telencephalon-ablated animals, suggesting histaminergic neurons of the telencephalon play a role in this task. Other authors indicate that CPA could be involved in fear/ anxiety processes in telencephalonless fish (Faganello and Mattioli, 2007), and show the role of mesencephalic structures in risk assessment behavior (Bertoglio and Zangroni, 2006). These data lead us to suggest that the incapacity to learn the proposed task could occur through fear of exploration of the maze in telencephalonless fish.

Our findings reinforce the possible action of CPA in other structures involved in spatial learning, most probably through the cerebellum and optic tectum. Recent findings suggest direct connections between the cerebellum and telencephalon that may constitute communication channel thata are involved in the coordination of non-motor tasks such as place memory (Vonderschen et al., 2002). As well, in a study carried out by Choich and colleagues (2004), the presence of $\mathrm{H}_{1}$ histamine-like receptors was demonstrated in teleost fish, which are primarily localized in the cerebellum and thalamus, in addition to the optic tectum and torus semicircularis, as in other vertebrates.

In conclusion, this work supports the evidence that blockade of histamine $\mathrm{H}_{1}$ receptors plays an inhibitory role in the learning and memory processes of a spatialchoice task through its action in caudal structures of the brain in teleost fish, and also confirms the previous hypothesis that the teleost telencephalon is involved in such mechanisms.

The data presented here might stimulate further research on mesencephalic histamine modulation of fear learning.

\section{ACKNOWLEDGEMENTS}

This work was funded by grants from the Coordenação de Aperfeiçoamento Pessoal de Nível Superior (CAPES) and from Conselho Nacional de Desenvolvimento Científico e tecnológico (CNPq). We thank Ms. Teresa de Fátima Fatori Piassi for technical assistance.

\section{REFERENCES}

1. BERTOGLIO LJ, ZANGROSSI HJ (2006) Involvement of dorsolateral periaqueductal gray $\mathrm{N}$ methyl-D-aspartic acid glutamate receptors in the regulation of risk assessment and inhibitory avoidance behaviors in the rat elevated T-maze. Behav Pharmacol 17: $589-596$

2. BLANDINA P, GIORGETTI M, BATTOLINI L, CECCHI M, TIMMERMAN H, LEURS R, PEPEU G, GIVANINI MG (1996) Inhibition of cortical acetylcholine release and cognitive performance by histamine $\mathrm{H}_{3}$ receptor activation in rats, $\mathrm{Br} \mathrm{J}$ Pharmacol 119: 1656-1664

3. BROGLIO C, RODRÍGUEZ F, SALAS C (2003) Spatial cognition and its neural basis in teleost fishes. Fish and Fisheries 4: 247-255

4. BROWN RE, FEDOROV NB, HAAS HL, REYMANN KG (1995) Histaminergic modulation of synaptic plasticity in area CA1 of rat hippocampal slices. Neuropharmacology 34: 181-190

5. BUTLER AB (2000) Topography and topology of the teleost telencephalon: a paradox resolved. Neurosci Lett 293: 95-98

6. CANGIOLI L, BALDI E, MANNAIONI PF, BUCHERELLI C, BLANDINA P, PASSANI MB (2002) Activation of histaminergic $\mathrm{H}_{3}$ receptor in the rat basolateral amygdala improves expression of fear memory and enhances acetylcholine release. Eur J Neurosci 16: 521-528

7. CHOICH JA, EL-NABAWI A, SILBERGELD EK (2004) Evidence of histamine receptors in fish brain using an in vivo $\left[{ }^{14} \mathrm{C}\right] 2$-deoxyglucose autoradiographic method and an in vitro receptor-binding autoradiographic method. Environ Res 94: 86-93

8. DE ALMEIDA MAMR, IZQUIERDO I (1986) Memory facilitation by histamine. Arch Int Pharmacodyn Ther 283: 193-198

9. DEMSKI LS, BEAVER JA (2001) Brain and cognitive function en teleosts fishes. In: Roth G, Wulliman MF 
(eds), Brain Evolution and Cognition. New York: Wiley. pp: 297-332

10. ERIKSSON KS, PEITSARO N, KARLSTEDT K, KASLIN J, PANULA P (1998) Development of histaminergic neurons and expression of histidine decarboxylase mRNA in the zebra fish brain in the absence of all peripheral histaminergic systems. Eur J Neurosci 10: 3799-3812

11. FAGANELLO FR, MATTIOLI R (2007) Anxiolyticlike effect of chlorpheniramine in inhibitory avoidance in goldfish submitted to telencephalic ablation. Prog Neuropsychopharmacol Biol Psychiatry 31: 269-74

12. FLOOD NC, OVERMIER JB, SAVAGE GE (1976) Teleost telencephalon and learning: an interpretive review of data and hypotheses. Physiol Behav 16: 783-798

13. HAAS H, PANULA P (2003) The role of histamine and the tuberomamillary nucleus in the nervous system. Neuroscience 4: 121-130

14. HOLLIS KL, OVERMIER JB (1982) Effect of telencephalon ablation on the reinforcing and eliciting properties of species-specific events in Betta splendens. J Comp Phys Psychol 96: 574-590

15. HUANG Y-W, HU W-W, CHEN Z, ZHANG L-S, SHEN H-Q, TIMMERMAN H, LEURS R, YANAI K (2004) Effect of histamine $\mathrm{H}_{3}$-antagonist clobenpropit on spatial memory deficits induced by MK-801 as evaluated by radial maze in Sprague-Dawley rats. Behav Brain Res 151: 287-293

16. INAGAKI N, PANULA P, YAMATODANI A, WADA $H$ (1991) Organization of histaminergic system in the brain of the teleost Trachurus trachurus. J Comp Neurol 310: 94-102

17. KAMEI C, OKUMURA Y, TASAKA K (1993) Influence of histamine depletion on learning and memory recollection in rats. Psychopharmacology 111: 376-382

18. KANDEL ER, SCHWARTZ JH, JESSELL TM (eds) (2000) Principles of neural science. New York: McGraw-Hill

19. KASLIN J, PANULA P (2001) Comparative anatomy of histaminergic and other aminergic systems in zebrafish (Danio rerio). J Comp Neurol 440: 342-377

20. LAMING PR, MCKEE M (1981) Deficits in habituation of cardiac arousal responses incurred by telencephalic ablation in goldfish, Carassius auratus, and their relation to other telencephalic functions. J Comp Phys Psychol 95: 460-467

21. LAMING PR, MCKINNEY SJ (1990) Habituation in goldfish (Carassius auratus) is impaired by increased interstimulus interval, interval variability, and telencephalic ablation. Behav Neurosci 104: 869-875

22. LEURS R, SMIT MJ, TIMMERMAN H (1995) Molecular pharmacological aspects of histamine receptors. Pharmacol Ther 66: 413-463

23. LIU Y, BRAUD WG (1974) Modification of learning and memory in goldfish through the use of stimulant and depressant drugs. Psychopharmacologia 35: 99-112

24. LÓPEZ JC, BINGMAN VP, RODRÍGUEZ F, GÓMEZ Y, SALAS C (2000a) Dissociation of place and cue learning by telencephalic ablation in goldfish. Behav Neurosci 114: 687-699

25. LÓPEZ JC, BROGLIO AC, RODRÍGUEZ F, THINUSBLANC C, SALAS C (2000b) Reversal learning deficit in a spatial task but not in a cued one after telencephalic ablation in goldfish. Behav Brain Res 109: 91-98

26. MATTIOLI R, NELSON CA, HUSTON JP, SPIELER RE (1998) Conditioned place preference analysis in the goldfish with the $\mathrm{H} 1$ histamine antagonist chlorpheniramine. Brain Res Bull 45: 41-44
27. MEDALHA CC, COELHO JL, MATTIOLI R (2000) Analysis of the role of histamine in inhibitory avoidance in goldfish. Prog Neuropsychopharmacol Biol Psychiatry 24: 295-305

28. MEDALHA CC, MATTIOLI R (2007) Involvement of histaminergic system on appetitive learning and its interaction with haloperidol in goldfish. Neurosci Lett 418(2): 195-200

29. MEGURO K, YANAI K, SAKAI N, SAKURAI E, MAEYAMA K, SASAKI H, WATANABE T. (1995) Effects of thioperamide, a histidine $\mathrm{H} 3$ antagonist, on the step through passive avoidance response and histidine decarboxylase activity in senescenceaccelerated mice. Pharmacol Biochem Behav 50: 321325

30. MIYAZAKI S, IMAIZUMI M, ONODERA K (1995) Ameliorating effects of histidine on scopolamineinduced learning deficits using an elevated plus-maze test in mice. Life Sci 56: 1563-70

31. MONTI JM (1993) Involvement of histamine in the control of waking state. Life Sci 53: 1331-1338

32. MORIMOTO T, YAMAMOTO Y, YAMATODANI A (2001) Brain histamine and feeding behavior. Behav Brain Res 124: 145-150

33. OHNISHI K (1997) Effects of telencephalic ablation on short-term memory and attention in goldfish. Behav Brain Res 86: 191-199

34. OVERMIER JB, CURNOW PF (1969) Classical conditioning, pseudoconditioning, and sensitization in "normal" and forebrainless goldfish. J Comp Phys and Psychol 68: 193-198

35. PASSANI MB, BACCIOTTINI L, MANNAIONI PF, BLANDINA P (2000) Central histaminergic system and cognition. Neurosci Biobehav Rev 24: 107-113

36. PASSANI MB, CANGLIOLI I, BALDI E, BUCHERELLI C, MANNAIONI PF, BLANDINA P (2001) Histaminergic $\mathrm{H}_{3}$ receptor-mediated impairment of contextual fear conditioning and in-vivo inhibition of cholinergic transmission in the rat basolateral amygdala. Eur J Neurosci 14: 1522-1532

37. PEEKE HV, GORDON DG (1981) Deficits in foraging behavior after telencephalon ablation in the goldfish (Carassius auratus). Exp Neurol 72: 204-210

38. PRAST H, ARGYRIOU A, PHILIPPU A (1996) Histaminergic neurons facilitate social memory in rats. Brain Res 734: 316-318

39. PORTAVELLA M, VARGAS JP, TORRES B, SALAS C (2002) THE EFFECTS of telencephalic pallial lesions on spatial, temporal and emotional learning in goldfish. Brain Res Bull 57: 397-9

40. PORTAVELLA M, VARGAS JP (2005) Emotional and spatial learning in goldfish is dependent on different telencephalic pallial systems. Eur J Neurosci 21: 28002806

41. RODRÍGUEZ F, DURÁN E, VARGAS JP, TORRES B, SALAS C (1994) Performance of goldfish trained in allocentric and egocentric maze procedures suggests the presence of a cognitive mapping system in fishes. Anim Learn Behav 22: 409-420

42. SALAS C, BROGLIO C, RODRÍGUEZ F, LÓPEZ JC, PORTAVELLA M, TORRES B (1996a) Telencephalic ablation in goldfish impairs performance in a 'spatial constancy' problem but not in a cued one. Behav Brain Res 79: 193-200

43. SALAS C, RODRÍGUEZ F, VARGAS JP, DURÁN E, TORRES B (1996b) Spatial learning and memory deficits after telencephalic ablation in goldfish trained in place and turn maze procedures. Behav Neurosci 110: 965-980

44. SHINOZUKA K, WATANABE S (2004) Effects of 
telencephalic ablation on shoaling behavior in goldfish. Physiol Behav 81: 141-8

45. SPIELER RE, NELSON CA, HUSTON JP, MATTIOLI $\mathrm{R}$ (1999) Post-trial administration of $\mathrm{H}_{1}$ histamine receptor blocker improves appetitive reversal learning and memory in goldfish, Carassius auratus. Neurosci Lett 17: 5-8

46. TUOMISTO L, LOZEVA V, VALJAKKA A, LECKLIN A (2001) Modifying effects of histamine on circadian rhythms and neuronal excitability. Behav Brain Res 124: 129-135

47. VONDERSCHEN K, BLECKMANN H, HOFMANN
MH (2002) A direct projection from the cerebellum to the telencephalon in the goldfish, Carassius auratus. Neurosci Lett 320: 37-40

48. WEILER HT, STEINER H, HUSTON JP (1990) Plasticity in crossed and uncrossed tuberomammilary striatal projections in relation to recovery from behavioral asymmetries induced by hemivibrissotomy. Neuroscience 37: 463-469

49. WEILER HT, WAGNER U, HUSTON JP (1992) Unilateral lesion in the tuberomammillary nucleus region: behavioral asymmetries and effects of histamine precursor. Behav Brain Res 49: 167-173. 